\title{
Effects of Frontal Cortical Lesions on Mouse Striatum: Reorganization of Cell Recognition Molecule, Glial Fiber, and Synaptic Protein Expression in the Dorsomedial Striatum
}

\author{
Maciej Poltorak, Antonio S. Herranz, Jamesine Williams, Liverana Lauretti, ${ }^{a}$ and William J. Freed \\ Preclinical Neurosciences Section, Neuropsychiatry Branch, NIMH Neuroscience Center at St. Elizabeth's, Washington, \\ DC 20032
}

Brain injury induces trophic effects within adjacent tissue through an unknown molecular mechanism. One model of this lesion effect involves the enhanced outgrowth of neuronal processes from transplanted substantia nigra in animals with cerebral cortex lesions. Since cell recognition molecules are involved in the molecular mechanisms of contact between cells and surrounding extracellular matrix components, and are important in plasticity of the nervous system, we investigated changes in $L 1, N-C A M$, and tenascin, as well as synapse-associated proteins and gliosis, in the strlatum of mice with cortical lesions. The removal of somatosensory and motor cortex would be expected to produce changes predominantly in the dorsal striatum. Lesioned mice, however, showed a significant enhancement of both L1 and N-CAM immunostaining intensity only within the most medial-periventricular and dorsomedial parts of the striatum, as compared to the nonlesioned side. Tenascin expression was significantly decreased, but only in the most medial part of the striatum. The changes in intensity of immunostaining with L1, N-CAM, and tenascin did not diminish with time after lesioning. These changes in cell recognition molecule expression indicate a possible molecular basis of lesion-induced plasticity in neuronal circuits within the dorsomedial striatum. These changes were accompanied by decreased synapsin and synaptophysin expression, but without any significant change in neurofilament expression. In contrast, glial fibrillary acidic protein and vimentin immunoreactivities were increased in almost the entire striatum on the lesioned side. Therefore, the areas of changes in cell recognition molecule expression did not simply correlate to the increased astrogliosis or neuronal fiber damage. We postulate that the periventricular dorsomedial striatum is relatively sensitive to disturbances of corticostriatonigral circuits and, simultaneously, this striatal area has a unique ability to support and promote neurite growth.

\footnotetext{
Received June 2, 1992; revised Oct. 12, 1992; accepted Nov. 25, 1992

We are grateful to $H$. Eleanor Cannon-Spoor for help in tracing experiments: to Melitta Schachner, Bernd Gehring, and Louis Degennaro for their kind gift of antibodies; to Wayne Rasband for providing and assisting with the use of the image analysis program; and to Bonnie Dodd for editing the manuscript. A.S.H was supported in part by FISSS, Spain (exp. 90/5199).

Correspondence should be addressed to Maciej Poltorak, NIMH Neuroscience Center at St. Elizabeth's, Washington, DC 20032.

'Present address: Institute of Neurosurgery, Catholic University, Rome, Italy. Copyright (c) 1993 Society for Neuroscience $0270-6474 / 93 / 132217-13 \$ 05.00 / 0$
}

[Key words: cell adhesion molecule, cell recognition molecule, cortex lesion, regeneration, reafferentation, synaptic reorganization, gliosis, striatum]

Lesions of the frontal cortex increase the degree of reafferentation of adjacent dorsomedial striatum by substantia nigra (SN) grafts in the lateral ventricle of animals with unilateral SN lesions (Freed and Cannon-Spoor, 1988, 1989). This finding is consistent with other data that suggest that a relatively large degree of striatal reafferantation is obtained when $\mathrm{SN}$ grafts are placed in cortical lesion cavities (Bjorklund et al., 1980). The mechanism by which frontal cortical lesions influence the reinnervation of denervated striatum is not, however, known.

Brain injury causes secretion of soluble neuronal trophic factors (Nieto-Sampedro et al., 1982, 1984). It is conceivable that these factors influence adjacent brain tissue by altering the expression of substrate molecules that are involved in the promotion or inhibition of neural outgrowth. Indeed, recent in vitro studies have shown that the degree of neurite extension is modified by recognition of certain permissive (Tomaselli et al., 1986, 1988; Bixby et al., 1988) or repulsive (Schwah and Caroni, 1988) substrate molecules by growth cones. There are many families of extracellular matrix (ECM) and cell recognition molecules involved in such interactions (Schachner et al., 1990). Among them, two molecules, $\mathrm{L} 1$ and N-CAM, in general have a positive influence on neurite extension (Lagenaur and Lemmon, 1987; Bixby et al., 1988; Lemmon et al., 1989; Bixby and Zhang, 1990; Doherty et al., 1991; Poltorak et al., 1992). Mouse L1 molecule (Rathjen and Schachner, 1984) is related to rat NILE molecule (Stallcup et al., 1985), and also to chick NgCAM (Grumet et al., 1984). Mouse Ll molecule is not identical with the chick $\mathrm{NgCAM}$, since it shares only approximately $40 \%$ the amino acid sequence (Moos et al., 1988; Burgoon et al., 1991).

Another molecule, tenascin (Chiquet-Ehrismann et al., 1988; Kruse et al., 1985), which is related to chick cytotactin (Grumet et al., 1985), in vitro appears able either to promote or to inhibit neurite extension depending on various conditions, such as whether it is substrate bound or secreted as the soluble form (Spring et al., 1989; Faissner and Kruse, 1990; Grierson et al., 1990; Lochter et al., 1991). Since cell recognition molecules may be important in plasticity and synaptic remodeling in the CNS, we have investigated whether frontal cortical lesions induce changes in cell recognition molecules in the striatum of mice. It is possible that such changes could predispose certain areas of the striatum to neurite growth. 


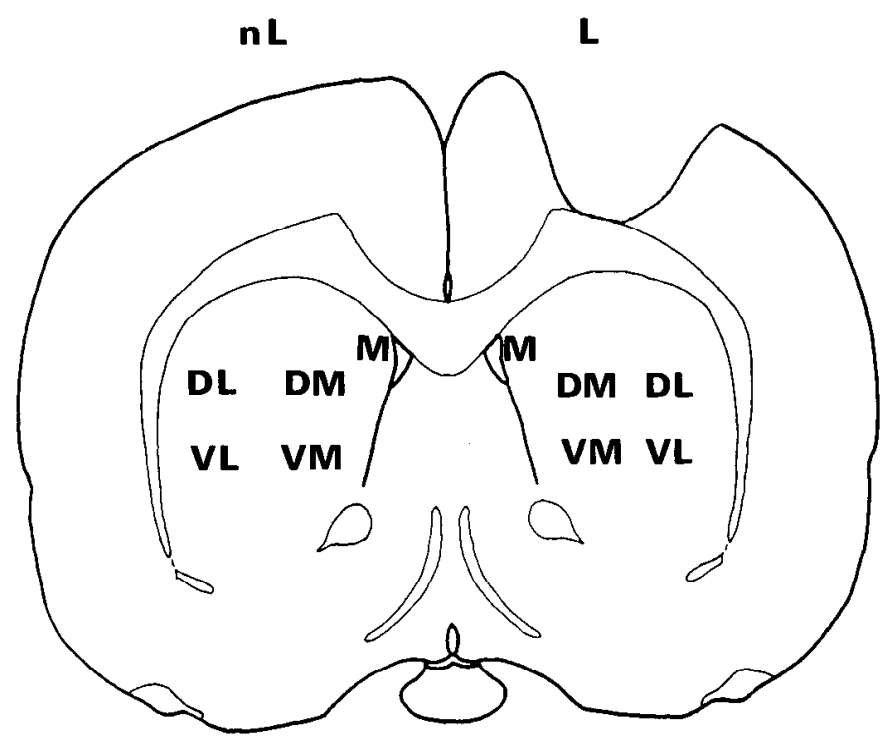

Figure 1. The location of an average aspiration lesion. For the purpose of this study, the striatum was arbitrarily divided into five regions: the most medial-periventricular part $(M)$ and the dorsomedial $(D M)$, dorsolateràl $(D L)$, ventrolateral $(V L)$, and ventromedial $(V M)$ quadrants. Measurements of mean staining intensity were taken from the both lesioned $(L)$ and nonlesioned $(n L)$ sides.

Synapsin and synaptophysin are important components of synaptic vesicles (reviewed in Sudnof and Jahn, 1991). Four related synapsin molecules are involved in the binding of synaptic vesicles to the cytoskeleton, and therefore guide the drift of synaptic vesicles between active and inactive zones of the presynaptic membrane. Synaptophysin is implicated in the formation of channels during synaptic vesicle exocytosis. Therefore, the expression of these proteins as measured by immunoreactivity can be used as an indication of synaptic density.

In order to examine the influence of frontal cortex extirpation on striatal tissue, we ablated the frontal cortex in mice without prior denervation of the striatum by $\mathrm{SN}$ lesions. We have investigated changes in cell recognition molecules, in addition to synapsin, synaptophysin, fibronectin, neurofilaments, and gliosis. To the best of our knowledge, data demonstrating the corticostriatal projection pattern are not available for mice, but refer only to the rat species, and there is a possibility of variation in the corticostriatal projection in the mouse. Since these data are critical for interpretation of the present results, wc also pcrformed anterograde tracing experiments to demonstrate the mouse frontocorticostriatal projection from the area of cortex that was lesioned.

\section{Materials and Methods}

Aspiration lesions of the right frontal cortex were performed in $48 \mathrm{CF} 1$ mice essentially as described in detail elsewhere (Freed and CannonSpoor, 1988). Animals were maintained according to the NIH Guide for Use of Laboratory Animals. Mice were housed in groups of 6-10 with continuous access to food and water, and were maintained on a $12 \mathrm{hr}$ light $/ 12 \mathrm{hr}$ dark cycle. Briefly, mice were anesthetized with ketamine and xylazine and mounted in a stereotaxic instrument. Cortical lesions were performed by aspiration of the cerebral cortex down to the corpus callosum under visual guidance. The lesions extended approximately from $0.5 \mathrm{~mm}$ from the midline to $2.5 \mathrm{~mm}$ laterally and $1 \mathrm{~mm}$ posterior from the bregma to the olfactory bulb. Following aspiration, bleeding was stopped with Gelfoam and the skin was closed with wound clips. The location of an average lesion is shown in Figure 1. Mice were studied after $5,10,21,100$, and $150 \mathrm{~d}$ of survival. Brains were quickly removed, frozen, and sectioned, and every seventh section was stained with cresyl violet. Matching frontal sections of anterior striatum from all groups were labeled with polyclonal rabbit serum against mouse L1 (Schachner et al., 1983; Rathjen and Schachner, 1984; dilution, 1:100), mouse N-CAM (Goridis et al., 1983; dilution, 1:100; both sera generous gifts of M. Schachner, Swiss Federal Institute of Technology, Zurich, Switzerland), human tenascin (Chemicon International Inc.; dilution, 1:100), and glial fibrillary acidic protein (GFAP; DAKO Corp.; dilution, $1: 400$ ), and rat synapsin I (Hamos et al., 1989; generous gift of L. DeGennaro, University of Massachusetts, School of Medicine, Worcester, MA; dilution, 1:200). We also used mouse monoclonal antibodies against neurofilaments SMI 31 and SMI 35 (Sternberger-Meyer Inc.; dilutions, 1:200), vimentin (clone 3D3, Chemicon; dilution, 1:50), and synaptophysin (Boehringer Mannheim Corp., clone SY 38; dilution ,1: 100 ). Indirect immunofluorescence was used as the detection system essentially according to Schachner (1983). The secondary antibodics were affinity purified swine anti-rabbit IgG (DAKO) or goat anti-mouse IgM (Pel-Freez) conjugated with rhodamine, or $F\left(a b^{\prime}\right) 2$ fragments of goat anti-mouse IgG (Pel-Freez) conjugated with fluorescein. Secondary antibodies were used at 1:75 to 1:200 dilutions. For each primary antibody, a matched set of sections from all of the treatment groups was selected and were stained simultaneously in a single batch.

Measurements of mean staining intensity were taken from both lesioned and nonlesioned sides. For the purpose of the study, the striatum was arbitrarily divided into five regions: the most medial-periventricular part (M), and the dorsomedial (DM), dorsolateral (DL), ventrolateral (VL), and ventromedial (VM) quadrants (see Fig. 1). The medial-periventricular (M) region was defined as the area medial to the myelinated fiber bundles. Mean density of immunostaining was measured using the Macintosh IIx-based image analysis program (IMAGE 1.33, developed by W. Rasband, NIMH, Bethesda, MD). The stained slides were studied under $200 \times$ magnification using a Zeiss Photomicroscope III, and a DAGE-MTI SIT68 camera. Fluorescence intensity was measured in relative gray scale units with the camera sensitivity adjusted so that the range of average mean fluorescence intensity for each antibody was approximately $120-250$ gray scale units. The lower range of gray scale $(0-120$ units) could not be effectively used because, at this sensitivity, anatomical regions could not be precisely identified.

Statistics. Statistical analyses were performed with the superanova program (Abacus Concepts, version 1.1). For each of the antibodies for which staining was measured in terms of staining intensity (L1, N-CAM, tenascin, synapsin, synaptophysin, fibronectin, GFAP, vimentin, and neurofilaments), the data were analyzed by a three-way analysis of variance (ANOVA), using side (lesioned vs nonlesioned) and rcgion (M, DM, DL, VL, and VM) as within-subjects factors and time after lesioning $(5,10,21,100$, and $150 \mathrm{~d})$ as a between-subjects factor. Differences between the lesioned and nonlesioned side for each of the five regions were tested by planned means contrasts. Other statistical tests were used as indicated.

Tracing. Tracing experiments to establish the corticostriatal projection from the lesioned area were performed using injections of Phaseolus vulgaris leucoagglutinin (PHA-L; Vector Labs) and wheat germ agglutinin conjugated to horseradish peroxidase (WGA-HRP; Sigma Chemical Co.) in young naive adult mice. The tracers were delivered iontophoretically with positive pulses of $1-7 \mu \mathrm{A}$ ( $7 \mathrm{sec}$ on, $7 \mathrm{sec}$ off, 75 cycles) from $2 \%$ solutions through glass pipettes with tip diameters of $20-25$ $\mu \mathrm{m}$. The injection sites were aimed at the same area of frontal cortex where the frontal aspiration lcsions wcre madc, and more medially into the cingulate cortex. Sections from mouse brains $(n=4)$ with the PHA-L injections were stained immunocytochemically according to the method of Gerfen and Sawczenko (1984) after 14 d of survival. WGA-HPR was visualized according to the method described by Mesulam (1982) with tetramethylbenzidine as the peroxidase substrate. Mouse brains $(n=6)$ were studied after $48 \mathrm{hr}$.

\section{Results}

Tracing experiments. The iontophoretic injections of both WGAHPR or PHA-L traccrs antcrogradely labeled the frontocorticostriatal pathway. The medial aspect of motor and somatosensory cortex (the site of the aspiration lesions) projected predominantly to the $\mathrm{DL}$ region of the striatum, with little or no labeling of the DM and M striatum (Fig. $2 A, B$ ). The tracer injections to the cingulate cortex at the level of the anterior 

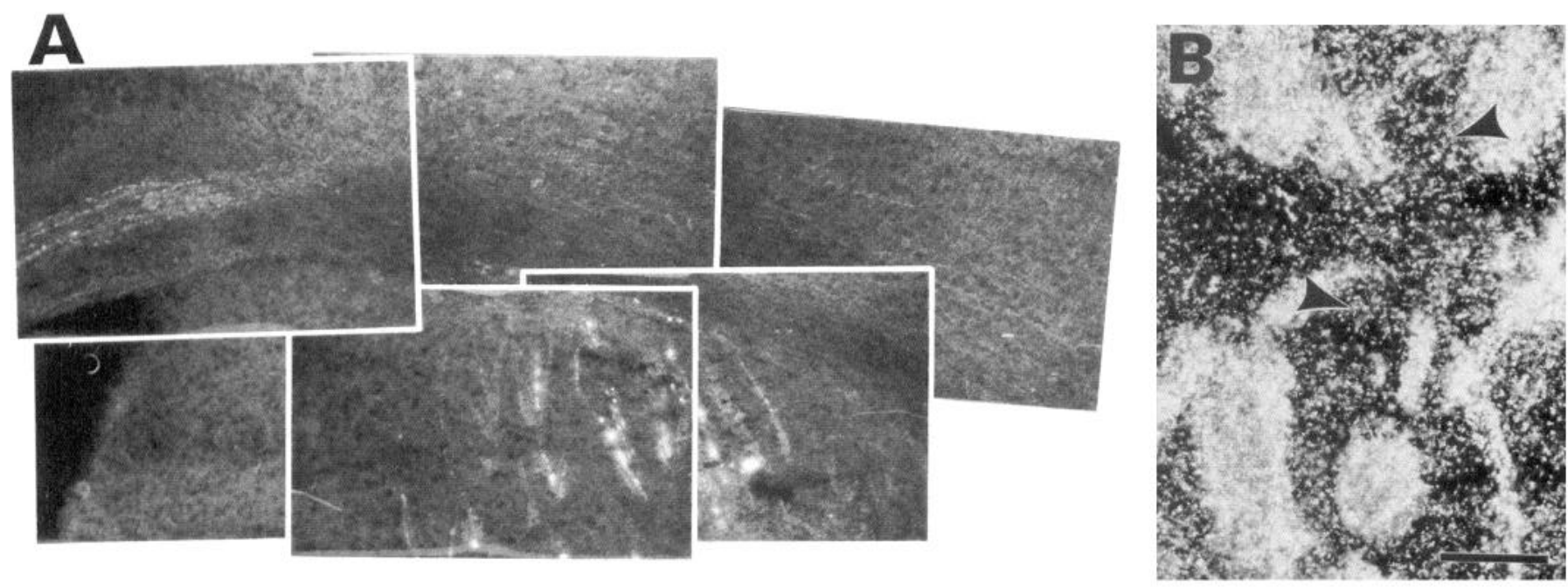

Figure 2. PHA-L $(A)$ and WGA-HRP $(B)$ anterograde labeling of the striatum after injection of tracers into the frontal cortex of naive mice at the same location in which the aspiration lesions were performed. The labeling indicates that the lesions removed output fibers projecting predominantly to the DL striatum. In $B$, taken from the DL region, at higher magnification, note that in addition to the fiber bundles there are also dispersed very fine fibers (arrowheads). Scale bar: $200 \mu \mathrm{m}$ for $A ; 50 \mu \mathrm{m}$ for $B$.

striatum produced labeling of more medial parts of the striatum (not shown).

L1 immunoreactivity. $\mathrm{L} 1$ immunoexpression within the striatum showed uniform staining of the brain parenchyma, with unstained cell bodies. The striatum on the lesioned side demonstrated disturbances of $\mathrm{L} 1$ immunoreactivity. In the $\mathrm{M}$ and $\mathrm{DM}$ regions on the lesioned side it appeared that $\mathrm{L} 1 \mathrm{immu}-$ noreactivity was more intense than on the nonlesioned side (Figs. $3 A-D ; 4 A, B$ ). Moreover, it seemed that in groups of mice with short survival times (i.e., 5 and $10 \mathrm{~d}$ ), in some of animals, there was a decrease of $\mathrm{L} 1$ immunoreactivity within the DL regions on lesioned side as compared to nonlesioned side (Fig. $3 E, F)$. In order to evaluate these findings statistically, we analyzed the $\mathrm{L} 1$ immunoreactivity using computer-assisted image analysis. The three-way ANOVA showed a statistically significant side $\times$ region interaction effect $[F(4,120)=3.21, p=$ $0.015]$. There was trend in the main effect of region $[F(4,120)$ $=2.24, p=0.069$ ]. The main effects of time and of side, and the interactions involving time, were not significant $(p>0.1)$. Means contrasts demonstrated a statistically significant enhancement of $\mathrm{Ll}$ immunostaining on the lesioned side in the $\mathrm{M}(p=0.04)$ and DM $(p=0.0004)$ regions, as compared to the nonlesioned side (Fig. $5 A$ ). There were no differences in the other regions, including DL. There were no statistically significant changes related to the time after lesioning.

$\mathrm{N}$-CAM immunoreactivity. Immunostaining with the N-CAM antibodies showed a homogeneous pattern within the striatum on both the lesioned and nonlesioned sides. It appeared that $\mathrm{N}$-CAM expression was enhanced on the lesioned side, as compared to the nonlesioned side, within the $\mathrm{M}$ and $\mathrm{DM}$ regions. Representative N-CAM immunostaining in the $\mathrm{M}$ region is shown in Figure 4, $C$ (nonlesioned side) and $D$ (lesioned side). This difference in immunostaining intensity was statistically significant. The three-way ANOVA showed a statistically significant side $\times$ region interaction effect $[F(4,128)=3.41, p=$ $0.01]$. There was a significant main effect of region $[F(4,128)=$ $4.67, p=0.015]$. The main effect of time and the interactions involving time were not significant. Means contrasts demonstrated a significant enhancement of N-CAM immunostaining on the lesioned side in the M $(p=0.04)$ and DM $(p=0.001)$ regions as compared to the nonlesioned side (Fig. $5 B$ ). There were no differences between the lesioned and nonlesioned sides in the other locations. No significant changes related to time after lesioning were found.

Tenascin immunoreactivity. The antibody against tenascin weakly stained the striatal tissue. Representative immunostaining with the tenascin antibody in the $\mathrm{M}$ region is shown in Figure 4, $E$ (nonlesioned side) and $F$ (lesioned side). It seemed that in $\mathrm{M}$ region on the lesioned side there was tendency for reduction of tenascin expression as compared to the nonlesioned side. The decreased intensity of tenascin immunoreactivity within the $M$ region was statistically significant. The three-way ANOVA showed a statistically significant side $\times$ region interaction effect $[F(4,120)=2.72, p=0.033]$. There was a significant main effect of region $[F(4,120)=6.69, p=0.0001]$. The main effect of time and the interactions involving time were not significant. Means contrasts demonstrated a decrease in tenascin immunostaining in the $\mathbf{M}(p=0.0001)$ region as compared to the nonlesioned side (Fig. $5 C$ ). There were no differences between the lesioned and nonlesioned sides in the other locations. Intensity of immunostaining did not show significant changes related to time after lesioning.

GFAP and vimentin immunoreactivity. After 5,10 , and $21 \mathrm{~d}$, mice showed enhancement of both GFAP and vimentin immunoreactivity on the lesioned side, as compared to the nonlesioned side, in almost the entire striatum with the exception of the VM region. After 100 and 150 d, expression of both GFAP and vimentin was similar on both sides in all regions. Figures 6 and 7 show representative GFAP immunolabeling. Vimentin immunoreactivity is not shown.

In order to quantify these findings, we counted the number of GFAP-positive cells in one field as seen with the fluorescence microscope at $312.5 \times$ magnification in each of the four regions DM, DL, VM, and VL. The data were analyzed using a threeway ANOVA. The main effect of side was statistically significant $[F(1,66)=38.89, p=0.001]$, as were the side $\times$ time $[F(4,66)$ $=5.39, p=0.0035]$ and the side $\times$ region interactions $[F(3,66)$ $=7.07, p=0.0003]$. The increase was statistically significant 

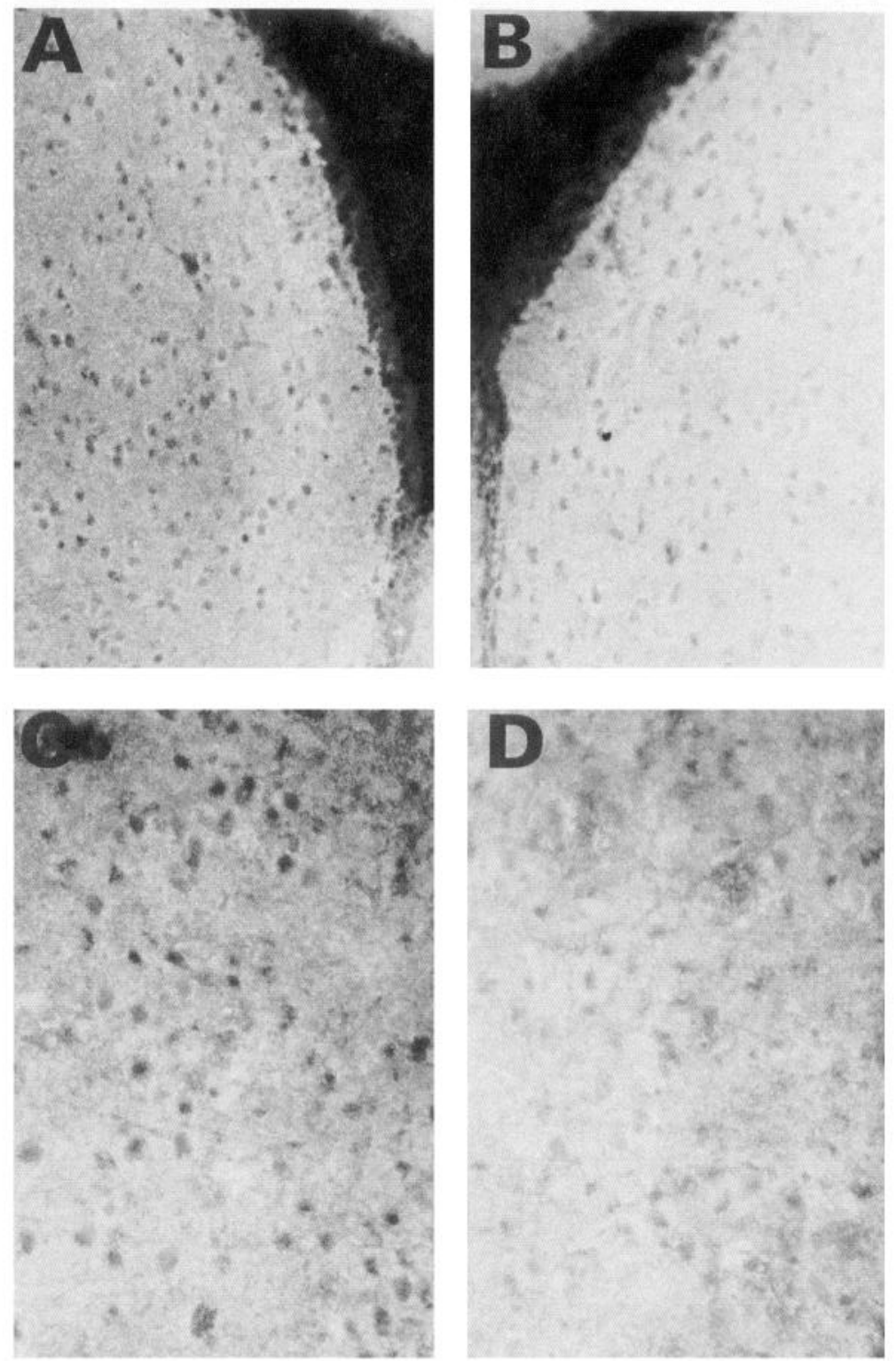

Figure 3. Comparison of immunostaining with the $\mathrm{Ll}$ antibodies on nonlesioned $(A, C, E)$ and lesioned side $(B, D, F)$, in the $\mathrm{M}$ region $(A, B), \mathrm{DM}$ region $(C, D)$, and $\mathrm{DL}$ region $(E, F)$. It appeared that there was an increase in immunostaining intensity within the $\mathbf{M}$ and DM region on the lesioned side as compared to the nonlesioned side. In some animals, it seemed that there was a reduction in $\mathrm{L} 1$ immunoreactivity in the DL region on the lesioned side; this latter difference was not confirmed quantitatively by image analysis (see Results). Scale bar: $90 \mu \mathrm{m}$ for $A$ and $B$; $50 \mu \mathrm{m}$ for $C-F$.
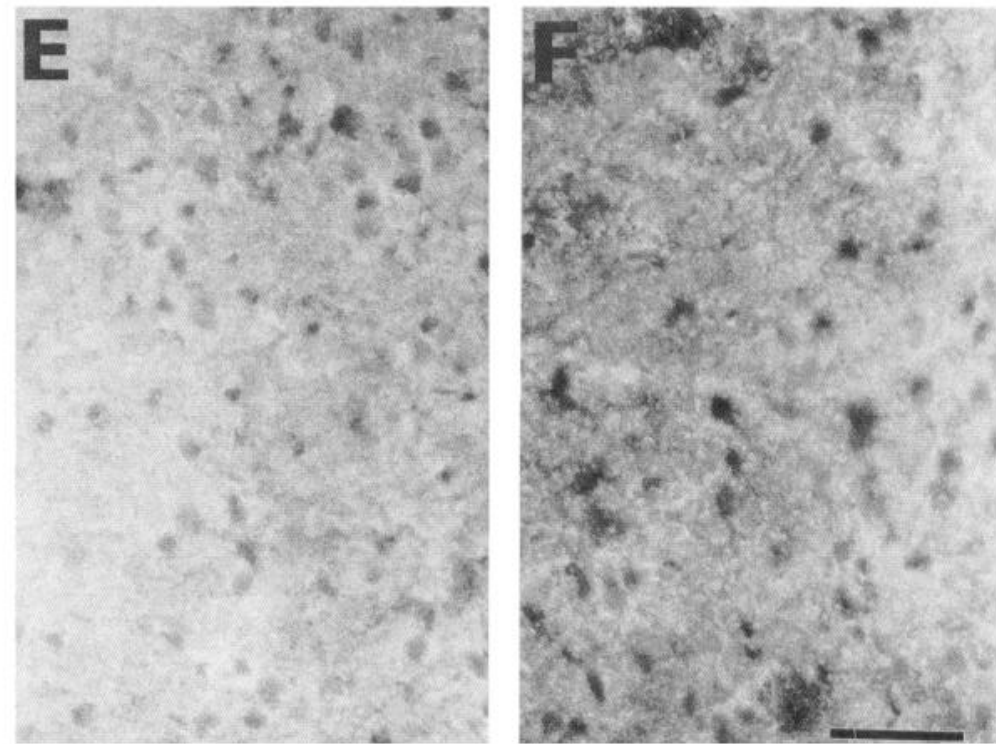

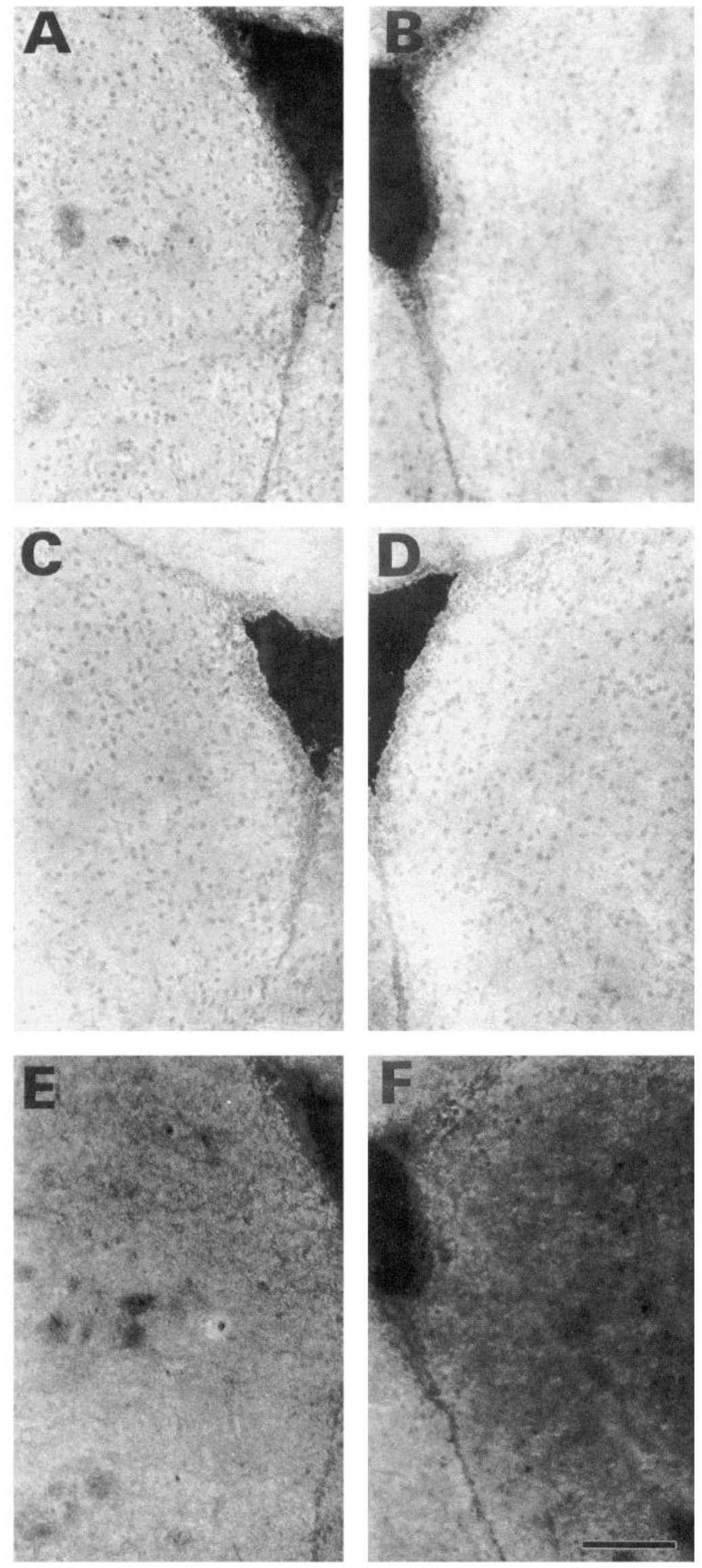

Figure 4. Representative immunostaining with the $\mathrm{L} 1(A, B), \mathrm{N}-\mathrm{CAM}(C$, $D)$, and tenascin $(E, F)$ antibodies in the $\mathrm{M}$ region (same brain sections) on the nonlesioned side $(A, C, E)$ and the lesioned side $(B, D, F)$ after $5 \mathrm{~d}$ of survival. $\mathrm{L} 1$ and $\mathrm{N}-\mathrm{CAM}$ immunostaining is increased, whereas tenascin immunostaining is decreased on the lesioned side. Scale bar, $125 \mu \mathrm{m}$. 

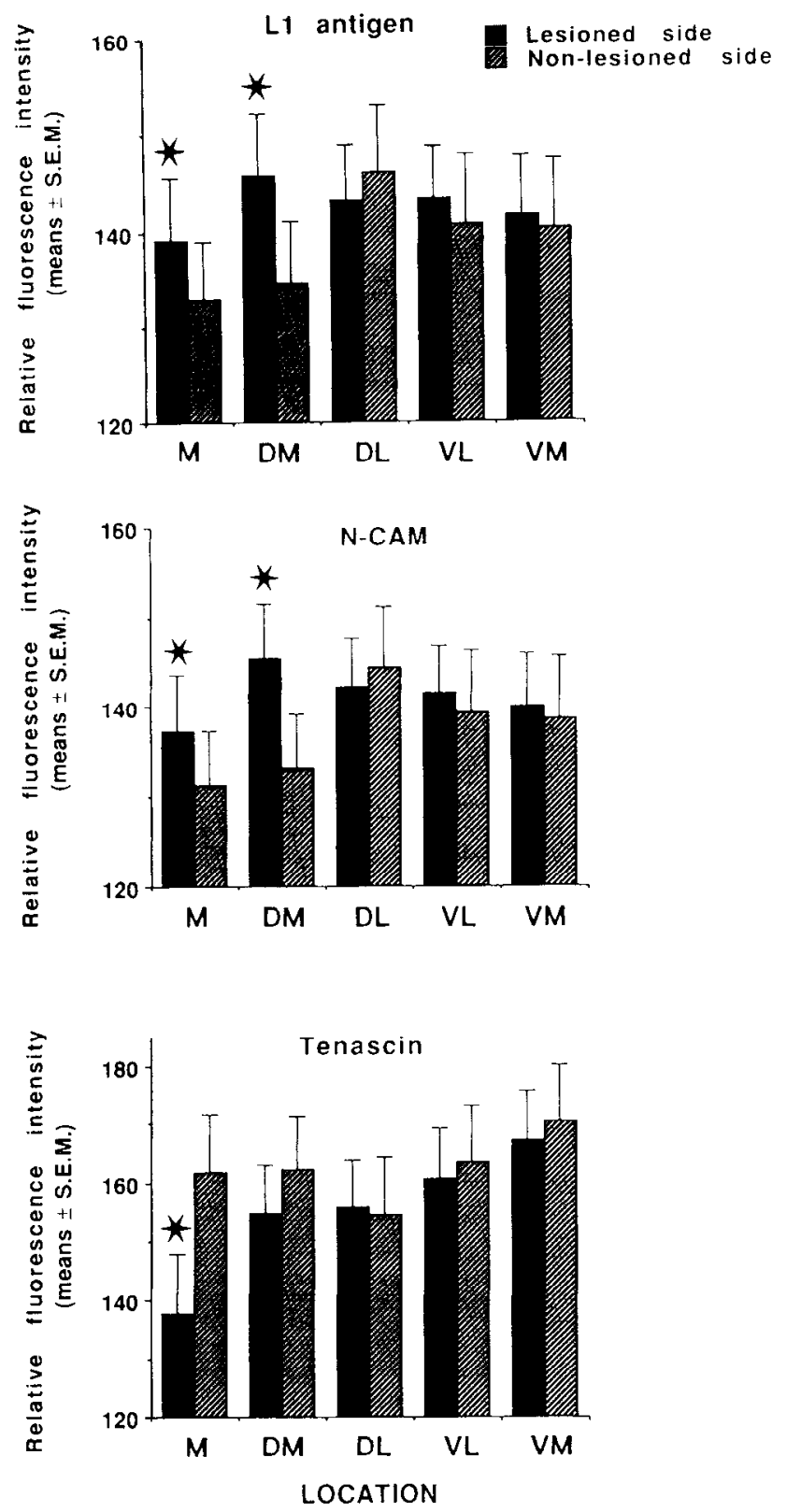

Figure 5. Quantitative computer analysis of the relative intensity of L1, N-CAM, and tenascin immunofluorescence. L1 antigen, The lesioned side of the $M$ and DM regions of the striatum showed a statistically significant enhancement of $\mathrm{L} 1$ immunostaining as compared to the nonlesioned side. Intensity of immunostaining did not show significant changes related to time after the lesions. N-CAM, The lesioned side in the $M$ and DM regions showed a statistically significant enhancement of N-CAM immunostaining as compared to the nonlesioned side. Intensity of immunostaining did not change significantly with time after lesioning. Tenascin. The most $\mathrm{M}$ region showed a statistically significant decrease in tenascin immunostaining on the lesioned side as compared to the nonlesioned side. Intensity of immunostaining did not show significant changes related to time after the lesions. Asterisks indicate statistically significant differences. Abbreviations are as in Figure 1 .

for the DM region after $5 \mathrm{~d}(p=0.0075), 10 \mathrm{~d}(p=0.0001]$ and $21 \mathrm{~d}(p=0.0001)$, but not after 100 and $150 \mathrm{~d}$. For the DL region, the effect of side was significant after $5 \mathrm{~d}(p=0.0001)$, $10 \mathrm{~d}(p=0.0001)$, and $21 \mathrm{~d}(p=0.005)$, but not after 100 and $150 \mathrm{~d}$. For the VL quadrant, the effect was significant after 10 $\mathrm{d}(p=0.0001)$ and $21 \mathrm{~d}(p=0.037)$ but not after 5, 100, and
$150 \mathrm{~d}$. For the VM region, the effect was only significant after $10 \mathrm{~d}(p=0.04)$. Results are shown in Figure 8.

In addition, a strong enhancement of both GFAP and vimentin immunoreactivity was seen in the periventricular dorsomedial striatum. This GFAP and vimentin staining appeared in a fibrillar pattern, with fibers generally radiating outward from the ventricle. The lesion appeared to both increase the density of the GFAP and vimentin-positive fibers along the ventricular wall, and also to increase the distance to which these fibers extended outward into the DM striatum from the ventricle (see Fig. 6). In order to quantify this effect, the areas of increased periventricular GFAP and vimentin staining were manually traced, using the computer, on the lesioned and nonlesioned sides. The data were analyzed by a two-way ANOVA. For GFAP immunoreactivity, the main effect of side was statistically significant $[F(1,23)=32.74, p=0.0001]$ as was the side $\times$ time interaction $[F(4,23)=6.80, p=0.0009]$. The increase in the area of periventricular GFAP immunoreactivity was significant after $5 \mathrm{~d}(p=0.001)$, nonsignificant after $10 \mathrm{~d}(p=0.059)$, significant after $21 \mathrm{~d}(p=0.0001)$, and nonsignificant after 100 and $150 \mathrm{~d}$. For periventricular vimentin immunostaining, the main effect of side was also statistically significant $[F(1,24)=$ $34.26, p=0.0001]$, but the side $\times$ time interaction was not. The effect of side was significant after $5 \mathbf{d}(p=0.0001), 10 \mathrm{~d}(p$ $=0.017)$, and $21 \mathrm{~d}(p=0.001)$ but not after 100 and $150 \mathrm{~d}$. These data are summarized in Figure 9.

Synaptophysin and synapsin immunoreactivities. Both antibodies produced uniform strong staining within the striatal parenchyma. It seems that within the $M$ region there was a reduction of their immunostaining intensities. Computer analysis demonstrated that there was a decrease in expression of both synaptophysin and synapsin in the $M$ region on the lesioned side as compared to nonlesioned side. The side $\times$ region interaction was statistically significant for synapsin $[F(4,115)=3.04$, $p=0.01]$ and for synaptophysin $[F(4,135)=2.83, p=0.01]$. The decreased immunostaining in the $M$ region was statistically significant for both synapsin $(p=0.001)$ and synaptophysin $(p$ $=0.004$ ). The remaining four regions were not significantly altered (Fig. 10). There was no significant main effect of time, nor were the interactions involving time significant.

Fibronectin immunoreactivity. Fibronectin staining within the striatum was associated predominantly with the small vessels. Some weak specks of immunoreactivity were also seen dispersed within the striatal parenchyma (not shown). It appeared that there was an increase of intensity of staining within the DM, $\mathrm{DL}$, and VL regions on the lesioned side as compared to nonlesioned side. Image analysis showed that these differences were indeed statistically significant. A three-way ANOVA showed that the side $\times$ region interaction effect was statistically significant $[F(4,115)=3.58, p=0.004]$. Intensity of immunostaining was increased in the DM $(p=0.003)$, DL $(p=0.008)$, and VL $(p=0.04)$ regions on the lesioned side, as compared to the nonlesioned side. The $\mathrm{M}$ and the $\mathrm{VM}$ regions were not affected (Fig. 10). There was no significant effect of time.

Neurofilament immunoreactivities. Immunostaining with both the SMI 31 and SMI 35 antibodies did not show any apparent differences on the lesioned, as compared to the nonlesioned, side. Computer analysis of immunostaining intensities with both SMI 31 and SMI 35 antibodies confirmed that there were no significant main effects or interactions involving side (lesioned vs nonlesioned), region, or time (five time points) (data not shown). 

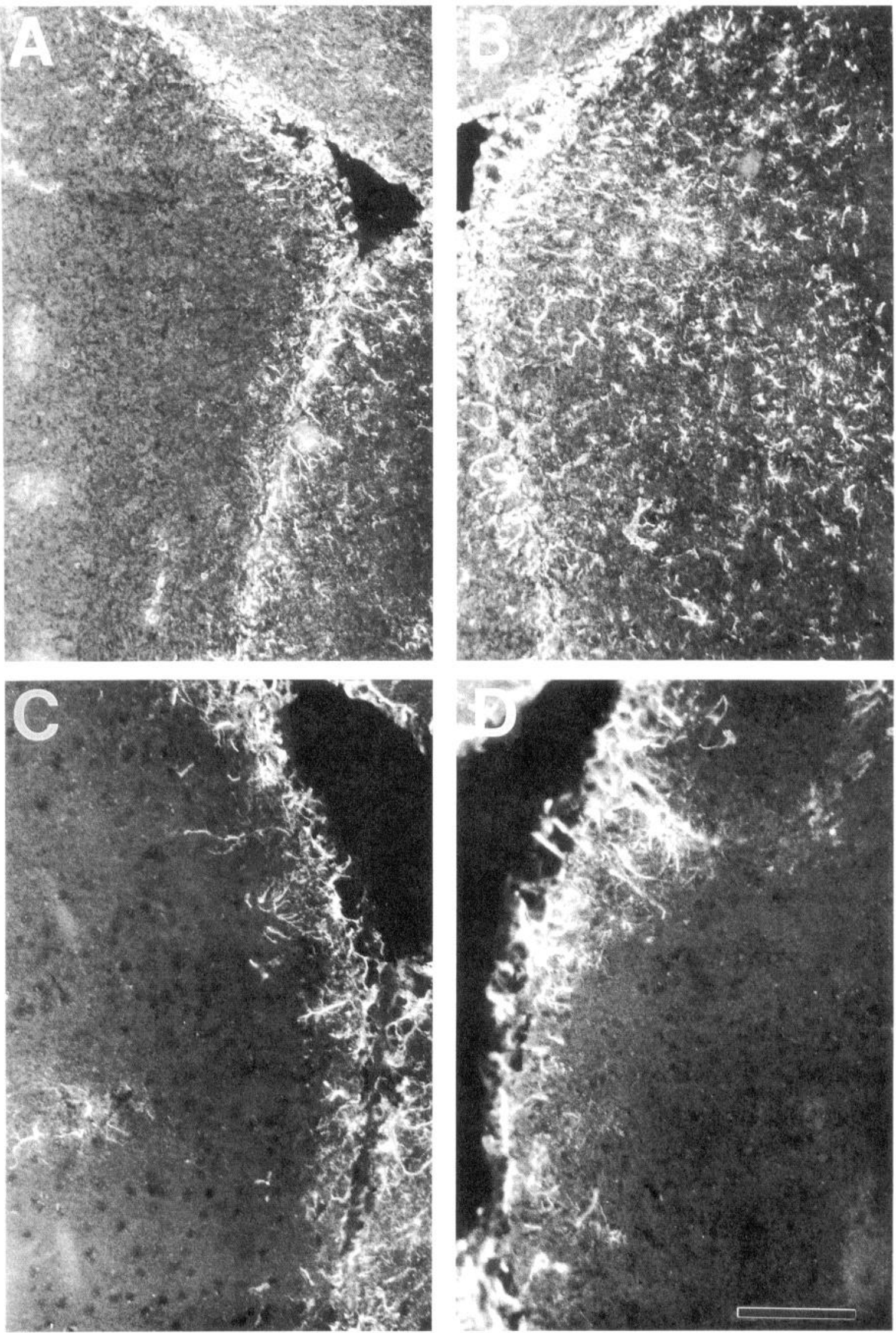

Figure 6. GFAP immunoreactivity. $A$ and $C$, nonlesioned side; $B$ and $D$, lesioned side. $A$ and $B$, after $5 \mathrm{~d}$ of survival; $C$ and $D$, after $100 \mathrm{~d}$ of survival. Mice showed enhancement of GFAP immunoreactivity on the lesioned side as compared to the nonlesioned side in almost the entire striatum, with the exception of the VM region. The photographs show representative GFAP immunolabeling in the M region after $5 \mathrm{~d}$. This periventricular GFAP immunoreactivity was most prominent after 5 and $10 \mathrm{~d}$ and was still present after $21 \mathrm{~d}$ of survival. However, after 100 and $150 \mathrm{~d}$ the increased GFAP expression disappeared and was similar on both sides $(C, D)$. Scale bar, $125 \mu \mathrm{m}$. 

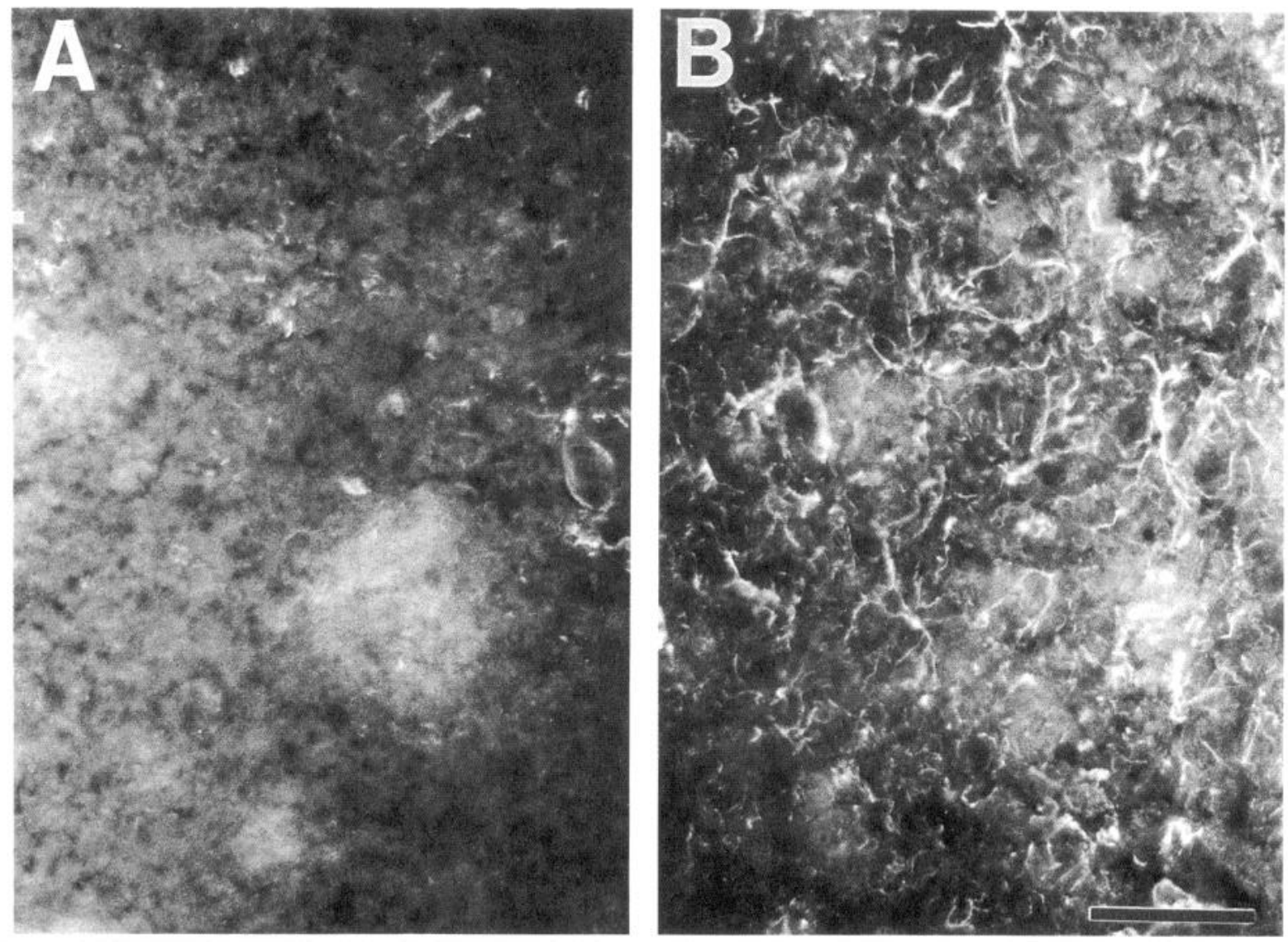

Figure 7. Illustration of increased GFAP immunoreactivity in the DL region of the striatum after $5 \mathrm{~d}$ of survival; $A$ is the lesioned side, and $B$ is the nonlesioned side. The general increase in GFAP staining was visible after 5,10 , and $21 \mathrm{~d}$ of survival but not after 100 and $150 \mathrm{~d}$ of survival. Scale bar, $125 \mu \mathrm{m}$.

\section{Location}

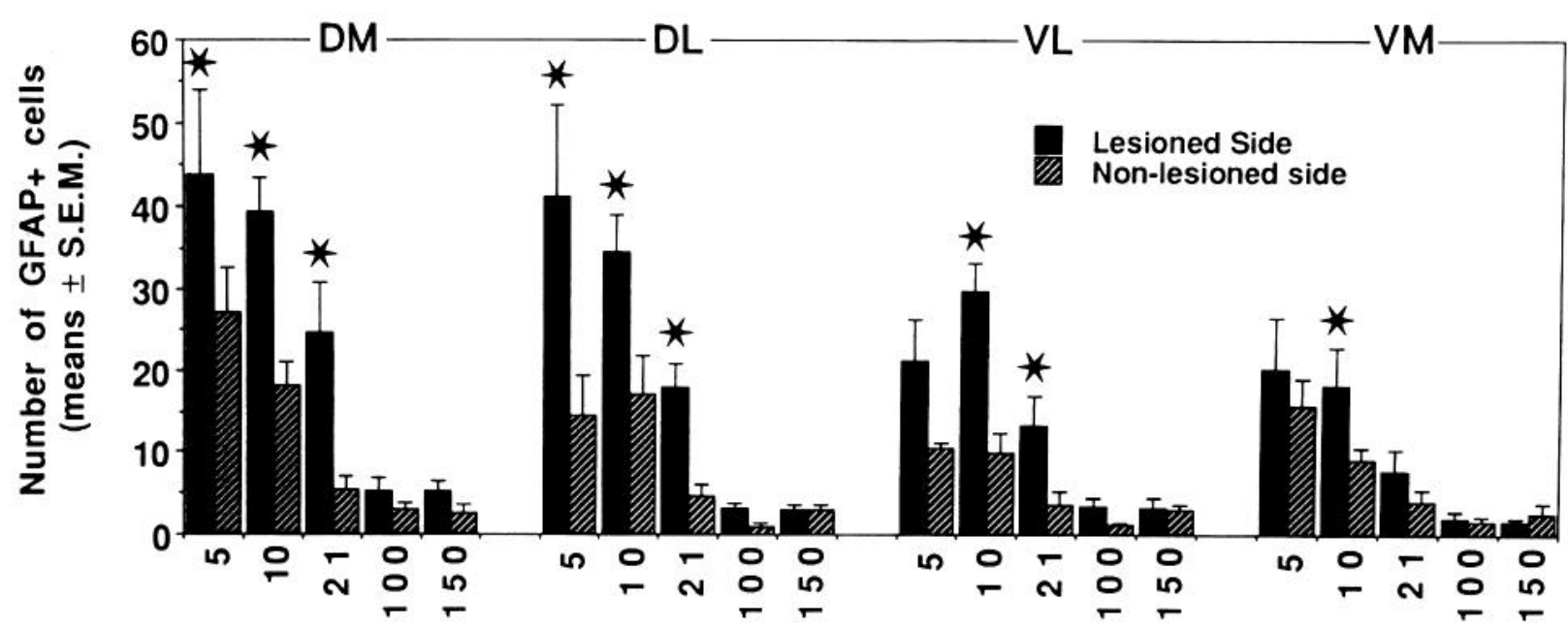

\section{Days}

Figure 8. Numbers of GFAP-positive cells in the DM, DL, VL, and VM regions, from the whole area seen with a fluorescence microscope under $312.5 \times$ magnification (i.e., in a rectangle with dimensions of $380 \mu \mathrm{m} \times 290 \mu \mathrm{m}$, total area $=110,200 \mu \mathrm{m}$ ). The effect of side was statistically significant for the DM quadrant after $5 \mathrm{~d}, 10 \mathrm{~d}$, and $21 \mathrm{~d}$ but not after 100 and $150 \mathrm{~d}$. For the DL quadrant, the effect of side was significant after 5,10 , and $21 \mathrm{~d}$ but not after 100 and $150 \mathrm{~d}$. For the VL quadrant the effect was significant after $10 \mathrm{~d}$ and $21 \mathrm{~d}$, but not after 5 , 100 , and $150 \mathrm{~d}$. For the VM quadrant, the effect was only significant after $10 \mathrm{~d}$. Details of the statistics are given in the Results. Asterisks indicate the statistically significant increases on the lesioned side as compared to the corresponding region of the nonlesioned side. 

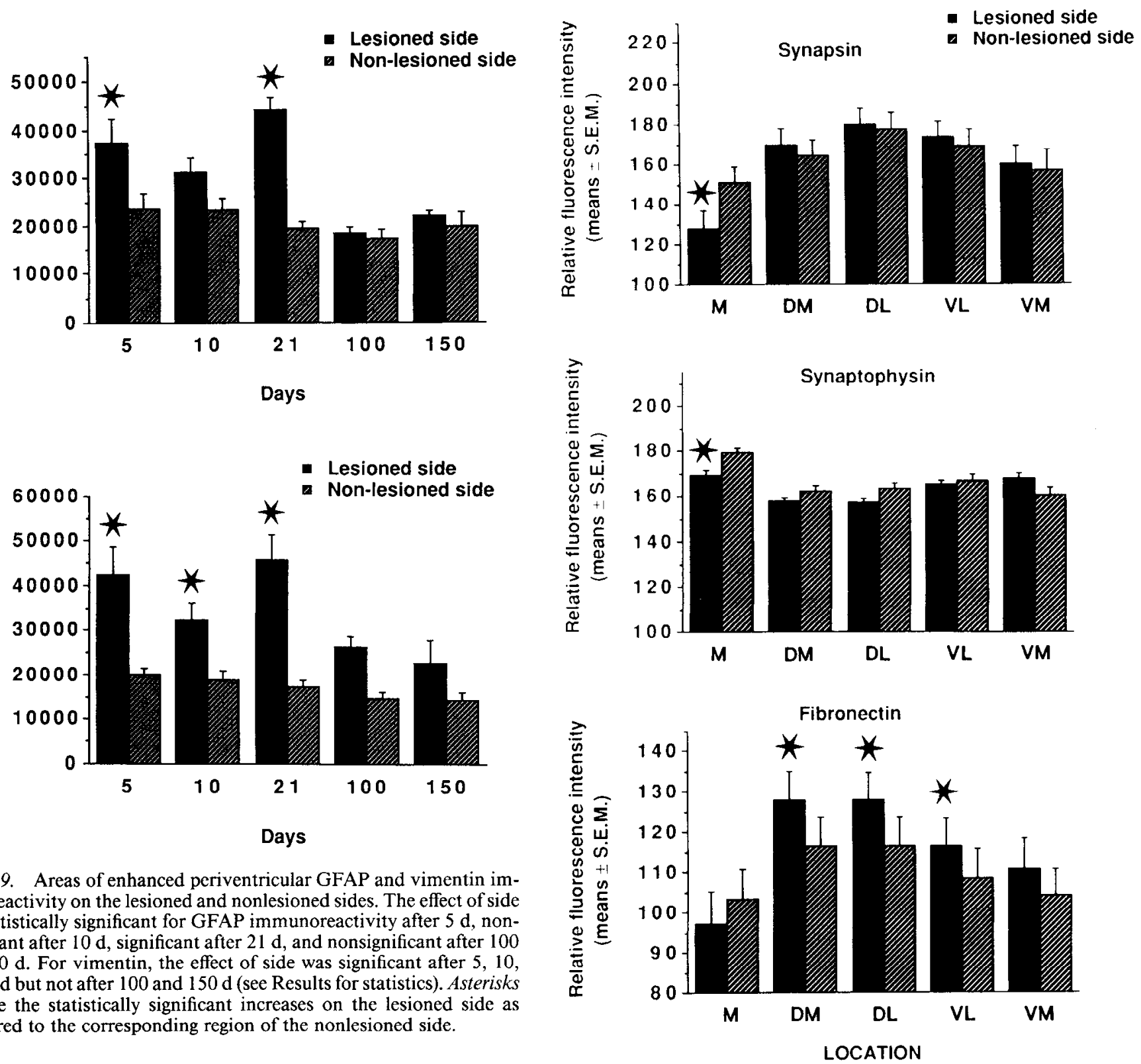

Figure 9. Areas of enhanced periventricular GFAP and vimentin immunoreactivity on the lesioned and nonlesioned sides. The effect of side was statistically significant for GFAP immunoreactivity after $5 \mathrm{~d}$, nonsignificant after $10 \mathrm{~d}$, significant after $21 \mathrm{~d}$, and nonsignificant after 100 and $150 \mathrm{~d}$. For vimentin, the effect of side was significant after 5, 10, and $21 \mathrm{~d}$ but not after 100 and $150 \mathrm{~d}$ (see Results for statistics). Asterisks indicate the statistically significant increases on the lesioned side as compared to the corresponding region of the nonlesioned side.

\section{Discussion}

$L 1$ and $N$-CAM expression is increased in $M$ and $D M$ regions. In contrast to the PNS, there are very little data on the influence of CNS damage on L1 and N-CAM expression. Recently, it has been reported that $\mathrm{SN}$ damage of neonatal mice did not increase expression of $\mathrm{Ll}$ and N-CAM in the striatum (O'Brien et al., 1992). Our results indicate that frontal cortical lesions provoked increases in both $\mathrm{L} 1$ and N-CAM expression in the M and DM regions of the striatum ipsilateral to the lesion, as comparcd to the nonlesioned side, although in other areas of striatum there were no significant changes in L1 and N-CAM expression.

The changes in LI and N-CAM expression after frontal lesions indicate a potential predisposition of deafferented striatal tissuc for neurite growth. Recently, it has been shown that L1 has a promoting effect on neurite outgrowth from tyrosine hydroxylase (TH)-positive neurons in mesencephalic cultures (Poltorak et al., 1992). The effect of N-CAM on mesencephalic cultures has not yet been studied. Generally, N-CAM substrates have a positive influence on neurite extension (Bixby et al., 1988; Do-

Figure 10. Computer analysis of immunostaining with synaptophysin, synapsin, and fibronectin antibodies. The lesioned mice showed decreased expression of both synaptophysin and synapsin in the $\mathrm{M}$ region on the lesioned side as compared to nonlesioned side. Staining in the remaining four regions was not significantly altered. There was no significant effect of time. For fibronectin, the lesioned mice showed increased intensity of immunostaining within the DM, DL, and VL regions on the lesioned side as compared to the nonlesioned side. The $\mathrm{M}$ and the VM regions were not affected. There was no significant effect of time. Asterisks indicate statistically significant differences. Abbreviations are as in Figure 1.

herty et al., 1991). Moreover, developing dopaminergic neurons demonstrate increased N-CAM immunoreactivity in vivo (Shults and Kimber, 1992). These results may in part explain data suggesting that frontal cortex lesions enhance the outgrowth of neuronal processes from transplanted $\mathrm{SN}$ within the corpus striatum of rats with SN lesions (Freed and Cannon-Spoor, 1988, 1989).

Tenascin expression was decreased in the $M$ region. During development of the nervous system, certain brain areas express 
tenascin immunoreactivity. It has been shown that these areas are nuclear or regional borders where neurite outgrowth is inhibited (Steindler et al., 1989, 1990). The developing striatum has such boundaries, whereas the normal adult striatum shows low tenascin immunoreactivity and has no boundaries similar to those observed in the barrel field cortex. After brain injury, tenascin/cytotactin expression increases in adjacent tissue, and it has been hypothesized that this enhancement is one factor impairing regeneration processes (Laywell and Steindler, 1991; McKeon et al., 1991). In our model, the areas of decreased tenascin are relatively far from the lesion. Therefore, the influence of frontal lesions on striatal tenascin levels is probably secondary to deafferentation, rather than a direct mechanical effect. Lesions of the $\mathrm{SN}$ decrease tenascin immunoreactivity in the striatum of neonatal mice (O'Brien et al., 1992). We did not find a statistically significant downregulation of tenascin in the striatum, except in the $M$ region. It is possible that removal of the cortical versus SN inputs to the striatum produces different effects on expression of tenascin, N-CAM, and L1, although it is also possible that the difference in developmental stage of the animals in the present study, as compared to the study by O'Brien et al. (1992), contributes to the difference in results. The relative lack of tenascin immunoreactivity in $\mathrm{M}$ region after frontal lesions may contribute to promotion of neurite outgrowth in the medial striatum.

Our data did not show significant changes in L1, N-CAM, or tenascin immunoreactivities related to time after lesioning. On the other hand, GFAP expression returned to normal after longer survival times. It is possible that the failure to find changes in cell recognition molecule expression related to time after lesioning is due to the relatively small number of animals in each time period studied.

Recently another molecule, chondroitin sulfate/keratan sulfate proteoglycan (CS/KS-PG), has been implicated in failure of regeneration in the CNS (McKeon et al., 1991). Similarly to tenascin, the CS/KS-PG molecule is expressed in boundary regions during development (Snow et al., 1990a) and inhibits neuronal growth (Snow et al., 1990b). Interestingly, injury of the adult brain produces a marked increase in expression of this molecule (McKeon et al., 1991). Whether disturbances in astrocyte synthesis of CS/KS-PG occur in the present injury model could be evaluated in the future.

Mechanism of observed changes in expression of cell recognition molecules. Although the changes in cell recognition molecules within the DM striatum after frontal cortex ablation suggest a possible molecular mechanism for facilitation of neurite outgrowth, they do not explain why these changes occur in these particular striatal regions, nor do they explain the mechanism responsible for their appearance. Lesions of the frontal cortex are assumed to have an impact on two main striatal pathways: first, they affect the corticospinal and thalamocortical projections passing through the putamen-caudate, and second, they remove corticostriatal glutamate projections (Carter, 1982). We will consider both factors subsequently.

Striatal fiber bundles do not influence changes in cell recognition molecule expression. In contrast to primates, in rodents the corticospinal bundles and thalamocortical pathways directly cross the putamen-caudate as fiber bundles. Damage to these fibers, by means of aspiration of their cell bodies, is likely to provoke demyelination and local micro- and astrogliosis within the bundles (Graeber et al., 1988; Streit and Kreutzberg, 1988; Poltorak and Freed, 1989). The $M$ region lacks these axonal bundles as compared to the rest of striatum. It does not seem likely that the changes in cell recognition molecule expression were caused entirely by changes within the fiber bundles. First, there was neither evident demyelination (not shown) nor a markedly increased cellularity within the bundles. Moreover, the GFAP-positive astrogliosis in the striatum on the lesioned side was primarily confined to the striatal parenchyma, not including the bundles (Figs. 6B, $7 B$ ). The probable reason that fiber bundles in the striatum were not greatly affected is that the bundles contain projections from very wide cortical areas, and therefore any individual bundle would include only a few damaged axons. Moreover, our cortical lesions were primarily limited to the medial aspect of frontal somatosensory cortex and relatively less motor cortex was damaged. The tissue aspiration removed primarily thalamocortical axonal terminals and sensory association neurons. Therefore, the cortical efferent axons in the bundles were not greatly damaged. These data suggest that changes in the fiber bundles might have only a minor influence on our results.

Lack of significant changes in cell recognition molecule expression in $D L$ striatum. The striatum is highly heterogeneous and contains distinct areas termed matrix and striatosomes or patches with complex input-output compartments (Graybiel and Ragsdale, 1983; Gerfen, 1984). In rodents, the corticostriatal fibers project bilaterally, particularly from the sensorimotor cortex (Carman et al., 1965). The excitatory glutaminergic cortical input to the striatum is widely distributed but has some degree of localization. In rats, the cingulate cortex projects predominantly to the DM striatum, whereas projections from motor and somatosensory fibers innervate dorsal and dorsolateral regions of striatum (Carter, 1982; Divac, 1983; Gerfen, 1984; Donoghue and Herkenham, 1986). Our lesions were confined primarily to the medial aspect of somatosensory and motor cortex, with only minor damage to the cingulate and prelimbic cortex. Tracing experiments using anterograde labeling with PHA-L and WGA demonstrated that, similar to the rat, there is no overlapping between the cingulate-striatal and somatosensory-striatal pathways in the mouse brain. The cortical areas that were removed were found to project primarily to the DL striatum. Changes in cell recognition molecule expression seen in the present study were primarily in the DM region, and especially in the very $M$ zone. The DL region was not changed.

This contradiction raises the possibility that we damaged the cingulate cortex and therefore destroyed neuronal cells that give rise to the corticostriatal projections to mediodorsal regions of striatum (Carter, 1982). Examination of cresyl violet-stained sections, however, revealed only minor and infrequent damage to the cingulate cortex. Moreover, decreases in the synaptic markers synapsin and synaptophysin were observed only in the $M$ region, and not in the other parts of the dorsal striatum. Furthermore, increased reactive gliosis was present not only within the DM region but covered almost the entire striatum on the lesioned side, and was absent in the striatum on the nonlesioned side.

Does the periventricular $M$ and $D M$ striatal region have unique properties? Increased GFAP and vimentin immunoreactivity was found in almost the entire striatum, except in the VM region. For most of the striatum, gliosis was present up to $21 \mathrm{~d}$ after lesioning, and declined to normal levels thereafter. Neither vimentin nor GFAP-positive gliosis was present in the striatum on the nonlesioned side. This reactive gliosis suggests that the areas of damage were not only confined to the $\mathrm{M}$ and DM 
regions. Thus, the areas of changed CAM expression did not correlate well either with the predicted areas of glutamatergic fiber deafferentation or with the areas of damage as indicated by gliusis.

Moreover, we also studied fibronectin immunoreactivity. Normal mature brain tissue demonstrates a low expression of fibronectin (Stewart and Pearlman, 1987). After brain injury there is an increase in fibronectin synthesis, not connected with neuroectodermal cells (Liesi et al., 1984). In our study there was a significant increase in fibronectin immunoreactivity in the striatum on the lesioned side, in DM, DL, and VL, but not in the $\mathrm{M}$ or VM regions, suggesting widespread damage in the striatum. This anatomical localization of increased fibronectin expression corresponds to the expected localization of corticostriatal deafferentiation produced by our lesions as well as to the areas of gliosis. It is noteworthy that fibronectin is generally considered to be a substrate that does not promote neuronal growth in the CNS (Rogers et al., 1989). Fibronectin has been found to facilitate the outgrowth of dopaminergic neurites in primary culture, although this effect appears to be dependent on glial cells (Poltorak et al.. 1992). The absence of an increase in the $\mathbf{M}$ region might contribute to facilitation of neurite outgrowth in this area.

The decrease in synaptic protein synthesis was primarily present in the $M$ striatum, where it would not be expected either theoretically, from expected areas of deafferentation, or from areas of increased GFAP, vimentin, and fibronectin staining. Any corresponding neurite damage must have been relatively small, since we did not observe significant changes in neurofilament expression. Thus, this region may be highly sensitive to disturbances of the corticostriatonigral circuits. This striatal area might also have a unique ability to support and promote neurite regeneration, since there is a concurrent increase in $\mathrm{Ll}$ and $\mathrm{N}$-CAM expression, a decrease in tenascin, and an absence of fibronectin upregulation.

The mechanism by which the effect of frontal cortex lesions is localized to the medial and dorsomedial striatum is unclear. There are at least two possibilities.

(1) Differential activation of striatal inputs. The potential explantation of the neurite-promoting effect of cortical lesions could be that neurotropic growth factors, particularly brainderived neurotropic factor (BDNF) might be released after lesioning. BDNF might mediate increased CAM expression or directly promote reafferention of the striatum by $\mathrm{SN}$ grafts. The survival of mesencephalic TH-positive neurons is dependent on the presence of regional non-neuronal cells (O'Malley et al., 1991) and striatal BDNF, which belongs to the NGF family (Hyman et al., 1991). Moreover, it is likely that the regulation of neurite extension from dopaminergic neurons in culture involves a combination of soluble growth factors (Tomazawa and Appel, 1986; Dal Toso et al., 1988; Collier et al., 1990; Engele and Bohn, 1991) and both ccll-cell and cell-ECM intcractions (Prochiantz et al., 1981; Heller and Won, 1985; Tomaselli et al., 1986; Walicke, 1988). Recent data suggests, at least in hippocampal cultures, that the synthesis of BDNF in neuronal cells is increased by activation of glutamate neurons synapsing with BDNF-synthesizing neurons, and decreased by GABA innervation (Zafra et al., 1991). Moreover, after temporal seizures synthesis of BDNF mRNA is increased in the hippocampal formation (Isackson et al., 1991). It is conceivable that BDNF production in the striatum is also regulated by glutamatergic inputs. In the case of frontal cortex lesions, the somatosensory glutamate neurons innervating DL striatum are removed, and would not amplify BDNF synthesis within the DL striatum. It is tempting to speculate that ablation of these somatosensory and motor cortical inputs to DL striatum may result in a compensatory activation of the remaining intact corticostriatal circuits including cingulate cortex, which, in turn, might stimulate synthesis of BDNF in medial and dorsomedial striatum. This hypothesis does not, however, explain why we observed a decrease in synaptic marker expression.

(2) Diffusion via the cerebrospinal fluid. Another possibility includes the potential influence of a factor(s) present in the CSF after frontal lesion. Removal of the frontal cortex may produce increased synthesis of soluble survival and neurite promoting factors (Nieto-Sampedro et al., 1982, 1984). Circulation of soluble factors via the cerebrospinal fluid (CSF), and possibly directly through tissue as well, may influence the adjacent $M$ and DM regions of striatum. The evidence of subependymal reactive astrogliosis (Fig. 4B,D) supports this possibility, and might explain the observation of gliosis in the medial striatum, which theoretically should not have been deafferented. CSF-borne factors might also induce changes in CAM expression that are primarily limited to the striatum adjacent to the lateral ventricle.

Unusual properties of $M$ and DM striatum in recovery of dopaminergic systems. Frontal cortex lesions, in our experimental paradigm, seem to precipitate a number of changes that are confined to the periventricular dorsomedial striatum. It is possible that this is related to recently observed regeneration of dopaminergic terminals of ventral tegmental area after tissue transplantation in experimental 1-methyl-4-phenyl-1,2,3,6-tetrahydropyridine (MPTP)-induced or in idiopathic parkinsonism in humans. Depending on dosage, the neurotoxin MPTP produces in mice and monkeys damage of $\mathrm{SN}$ dopaminergic neurons with the relative sparing of ventral tegmental areas (Burns et al., 1983; Hallman et al., 1985; Schneider et al., 1987). These dopaminergic fibers from the ventral tegmental area, which are less damaged and more likely to show regeneration, project mainly to the DM striatum. Several studies have shown regeneration or regrowth of dopaminergic fibers, primarily in the $M$ and DM regions according to our designation, after cortical and striatal injury or transplantation procedures (Bohn et al., 1987; Fiandanca et al., 1988; Bankiewicz et al., 1990; Kordower et al., 1990). Transplantation procedures, whether stereotaxic or open surgery, always induce cortical and striatal damage.

Moreover, our results could partially explain the behavioral amelioration of patients with Parkinson's disease after adrenal medulla transplants in the medial part of nucleus caudatus (M and DM region) (Madrazo et al., 1987). Although, the degree of improvement is controversial (Bjorklund, 1991), it has been confirmed in extensive studies by others (Goetz et al., 1989; Olanow et al., 1990). Reasons for the improvement are unclear, but postmortem studies (Hirsch et al., 1990; Kordower et al., 1992) also suggest neurite growth in this area. This neurite growth appears to be unrelated to graft survival, and may instead be related to the production of lesion cavities by the surgical procedures (Hirsch et al., 1990; Kordower et al., 1992). It is conceivable that similarly grafted embryonic SN in experimental and human parkinsonism also affects the DM striatum by altering expression of CAM molecules.

Concluding remarks. Our results suggest that frontal cortical lesions provoke an increase in both $\mathrm{L} 1$ and N-CAM expression and a decrease in tenascin immunoreactivity in the $M$ and DM regions of striatum on the lesioned side, as compared to the 
nonlesioned side. In addition to the changes in cell recognition molecule expression, there were decreases in the expression of synapsin and synaptophysin in the $\mathrm{M}$ region, and a peculiar enhancement of periventricular GFAP- and vimentin-positive glial fiber staining. Thus, there was a complex sct of alterations in the DM region and especially in the very medial-periventricular zone, which was not directly deafferented by the cortical lesions. This region appears, therefore, to be uniquely susceptible to alterations in the corticostriatal system, showing a complex reorganization of protein expression. These changes in cell recognition molecule expression indicate a possible molecular basis for plasticity in catecholamine-containing systems within the striatum, and may contribute to the outgrowth of neuronal processes from intraventricularly transplanted SN in the dorsomedial corpus striatum of rat hosts. Moreover, our results would suggest that the DM striatum in the mouse is relatively sensitive to disturbances of the corticostriatonigral circuits, and that this striatal area has a unique ability to support and promote neurite growth and plasticity.

\section{References}

Bankiewicz KS, Plunkett RJ, Jacobowitz DM, Kopin IJ, Oldfield EH (1990) Fetal nondopaminergic neural implants in parkinsonian primates. Histochemical and behavioral studies. J Neurosurg 74:97-104.

Bixby JL, Zhang R (1990) Purified N-cadherin is a potent substrate for the rapid induction of neurite outgrowth. J Cell Biol 110:12531260.

Bixby JL, Lilien J, Reichardt LF (1988) Identification of the major proteins that promote neuronal process outgrowth on Schwanns cell in vitro. J Cell Biol 107:353-361.

Bjorklund A (1991) Neural transplantation-an experimental tool with clinical possibilities. Trends Neurosci 14:319-323.

Bjorklund A, Dunnett SB, Stenevi U, Lewis ME, Iversen SD (1980) Reinnervation of the denervated striatum by substantia nigra transplants: functional consequences as revealed by pharmacological and sensorimotor testing. Brain Res 199:307-333.

Bohn MC, Marciano F, Cupit L, Gash DM (1987) Adrenal medullary grafts promote recovery of striatal dopaminergic fibers in MPTP treated mice. Science 237:913-916.

Burgoon MP, Grumet M, Mauro V, Edelman GM (1991) Structure of the chicken neuron-glia cell adhesion molecule, Ng-CAM: origin of polypeptides and relation to Ig superfamily. J Cell Biol 112:10171029.

Burns RS, Chiuech CC, Markey S, Ebert MH, Jacobowitz DM, Kopin IJ (1983) A primate model of parkinson's disease: selective destruction of substantia nigra pars compacta dopaminergic neurons by $N$-methyl-4-phenyl-1,2,3,6-tetrahydropyridine. Proc Natl Acad Sci USA 80:4546-4550.

Carman JB, Cowan WM, Powell TPS (1965) The organization of the cortico-striate projection. J Neurol Neurosurg Psychiatry 28:71-77.

Carter CJ (1982) Topographical distribution of possible glutamatergic pathways from the frontal cortex to the striatum and substantia nigra in rats. Neuropharmacology 21:379-383.

Chiquet-Ehrismann R, Kalla P, Pearson CA, Chiquet M (1988) Tenascin interferes with fibronectin action. Cell 53:383-390.

Collier TJ, Sladek CD, Gallagher MJ, Gereau IV, Springer JE (1990) Diffusible factor(s) from adult rat sciatic nerve increases cell number and neurite outgrowth of cultured embryonic ventral mesencephalic tyrosine hydroxylase-positive neurons. J Neurosci Res 27:394-399.

Dal Toso R, Giorgi O, Soranzo C, Kirschner G, Ferrari G, Favaron M Benvegnu D, Presti D, Vicini S, Toffano G, Azzone GF, Leon A (1988) Development and survival of neurons in dissociated fetal mesencephalic serum-free cell cultures. I. Effects of cell density and of an adult mammalian striatal-derived neuronotropic factor (SDNF). J Neurosci 8:733-745.

Doherty P, Rowett LH, Moore SE, Mann DA, Walsh FS (1991) Neurite outgrowth in response to transfected N-CAM and N-cadherin reveals fundamental differences in neuronal responsiveness to CAMs. Neuron 6:247-258.

Donoghue JP, Herkenham M (1986) Neostriatal projections from in- dividual cortical fields conform histochemically distinct compartments in the rats. Brain Res 365:397-403.

Engele J, Bohn MC (1991) The neurotrophic effects of fibroblast growth factors on dopaminergic neurons in vitro are mediated by mesencephalic glia. J Neurosci 11:3070-3078.

Faissner A, Kruse J (1990) J1/Tenascin is a repulsive substrate for CNS neurons. Neuron 5:627-635.

Fiandanca MS, Kordower JH, Hansen JT, Jiao SS, Gash DM (1988) Adrenal medullary autografts into the basal ganglia of Cebus monkeys: injury-induced regeneration. Exp Neurol 102:76-91.

Freed WJ, Cannon-Spoor HE (1988) Cortical lesions increase reinnervation of the dorsal striatum by substantia nigra grafts. Brain Res 46:133-143.

Freed WJ, Cannon-Spoor HE (1989) Cortical lesions interfere with behavioral recovery from unilateral substantia nigra lesions induced by brain grafts. Behav Brain Res 32:279-288.

Gerfen CR (1984) The neostriatal mosaic: compartmentalization of corticostriatal input and striatonigral output systems. Nature 311: $461-464$.

Gerfen CR, Sawczenko PE (1984) An anterograde neuroanatomical tracing method that shows the detailed morphology of neurons, their axons and terminals: immunohistochemical location of axonally transported plant lectin, Phaseolus vulgaris leucoagglutinin (PHA-L). Brain Res 290:219-238.

Goetz. CG, Olanow CW, Koller WC, Penn RD, Cahill D, Morantz R, Stebbins G, Tanner CM, Klawans HL, Shannon KM, Comella CL, Witt T, Cox C, Waxman M, Gauger L (1989) Multicenter study of autologous adrenal medullary transplantation to the corpus striatum in patients with advanced Parkinson's disease. N Engl J Med 320: 337-341.

Goridis C, Deagostini-Basin H, Hirn M, Hirsch MR, Rougon G, Sadoul R, Langley OK, Gombos G, Finne J (1983) Neural surface antigens during nervous system development. Cold Spring Harbor Symp Quant Biol 48:527-537.

Graeber MB, Tetzlaff W, Streit WJ, Kreutzberg GW (1988) Microglial cells but not astrocytes undergo mitosis following rat facial nerve axotomy. Neurosci Lett 85:317-321.

Graybiel AM, Ragsdale CW Jr (1983) Riochemical anatomy of the stratum. In: Chemical neuroanatomy (Emson PC, ed), pp 427-504. New York: Raven.

Grierson JP, Petroski RE, Ling DSF, Geller HM (1990) Astrocytc topography and tenascin/cytotactin expression: correlation with the ability to support neurite outgrowth. Dev Brain Res 55:11-19.

Grumet M, Hoffman S, Edelman GM (1984) Two antigenically related neuronal CAMs of different specificities mediate neuron-neuron and neuron-glia adhesion. Proc Natl Acad Sci USA 81:267-271.

Grumet M, Hoffman S, Crossin KL, Edelman GM (1985) Cytotactin, an extracellular matrix protein of neural and non-neural tissues that mediates glia-neuron interaction. Proc Natl Acad Sci USA 82:80758079.

Hallman H, Lange J, Olson L, Stromberg I, Jonsson G (1985) Neurochemical and histochemical characterization of neurotoxic effects of 1-methyl-4-phenyl-1,2,3,6-tetrahydropyridine on brain catecholamine neurones in the mouse. J Neurochem 44:117-127.

Hamos JE, DeGennaro LJ, Drachman DA (1989) Synaptic loss in Alzheimer's disease and other dementias. Neurology 39:355-361.

Heller A, Won L (1985) Selective association of dopaminergic (DA) axons with their striatal targets in vitro. Soc Neurosci Abstr 11:66.

Hirsch EC, Duyckaerts, Javoy-Agid F, Hauw JJ, Agid Y (1990) Does adrenal graft enhance recovery of dopaminergic neurons in Parkinson's disease? Ann Neurol 27:676-682.

Hyman C, Hofer M, Barde Y-A, Juhasz M, Yancopoulos GD, Squinto SP, Lindsay RM (1991) BDNF is a neurotrophic factor for dopaminergic neurons of the substantia nigra. Nature 350:230-232.

Isackson PJ, Huntsman MM, Murray KD, Gall CM (1991) BDNF mRNA expression is increased in adult rat forebrain after limbic seizures: temporal patterns of induction distinct from NGF. Neuron 6:937-948.

Kordower JH, Fiandaca MS, Notter MFD, Hansen JT, Gash DM (1990) NGF-like trophic support from peripheral nerve for grafted rhesus adrenal chromaffin cells. J Neurosurg 73:418-428.

Kordower JH, Cohran E, Penn RD, Goetz CG (1992) Putative chromaffin cell survival and enhanced host-derived TH-fiber innervation following a functional adrenal medulla autograft for Parkinson's disease. Ann Neurol 29:405-412. 
Kruse J, Keilhauer G, Faissner A, Timpl R, Schachner M (1985) The J1 glycoprotein - a novel nervous system cell adhesion molecule of L2/HNK-1 family. Nature 316:146-148.

Lagenaur C Lemmon V (1987) An L1-like molecule, the 8D9 antigen is a potent substrate for neurite extension. Proc Natl Acad Sci USA 84:7753-7757.

Laywell E, Steindler DA (1991) Boundaries and wounds, glia and glycoconjugates. Cellular and molecular analyses of developmental partitions and adult brain lesions. Ann NY Acad Sci 633:122-141.

Lemmon V, Farr KL, Lagenaur C (1989) LI-Mediated axon outgrowth occurs via a homophilic binding mechanism. Neuron 2:1597-1603.

Liesi P, Kaakkola S, Dahl D, Vaheri A (1984) Laminin is induced in adult rat brain astrocytes by stereotaxic lesioning. EMBO J 3:683686.

Lochter A, Vaughan L, Kaplony A, Prochiantz A, Schachner M, Faissner A (1991) J1/Tenascin in substrate-bound and soluble forms displays contrary effects on neurite outgrowth. J Cell Biol 113:1159-1171.

Madrazo I, Drucker-Colin, R, Diaz V, Martinez-Mata J, Torres C, Becerril JJ (1987) Open microsurgical autograft of adrenal medulla to the right caudate nucleus in two patients with intractable Parkinson's disease. New Engl J Med 316:831-834.

McKeon R, Schreiber RC, Rudge JS, Silver J (1991) Reduction of neurite outgrowth in a model of glial scarring following CNS injury is correlated with the expression of inhibitory molecules on reactive astrocytes. J Neurosci 11:3398-3411.

Mesulam MM (1982) Principles of horseradish peroxidase neurohistochemistry and their applications for tracing neural pathways-axonal transport, enzyme histochemistry and light microscopic analysis. In: Tracing neural connections with horseradish peroxidase (Mesulam MM, ed), pp 42-51. New York: Wiley.

Moos M, Tacke R, Scherer H, Teplow D, Fruh K, Schachner M (1988) Neural adhesion molecule $\mathrm{L} 1$ is a member of the immunoglobulin superfamily with binding domains similar to fibronectin. Nature 334: 701-703.

Nieto-Sampedro M, Lewis ER, Cotman CW, Manthorpe M, Skaper SD, Barbin G, Longo FM, Varon S (1982) Brain injury causes a time dependent increase in neuronotrophic activity at the lesion site. Science 217:860-861.

Nieto-Sampedro M, Whittemore SR, Needels DL, Larson J, Cotman CW (1984) The survival of brain transplants is enhanced by extracts from injured brain. Proc Natl Acad Sci USA 81:6250-6254.

O'Brien TF, Faissner A, Schachner M, Steindler DA (1992) Afferentboundary interactions in the developing neostriatal mosaic. Dev Brain Res 65:259-267.

Olanow CW, Koller W, Goetz CG, Stebbins GT, Cahill DW, Gauger LL, Morantz R, Penn RD, Tanner CM, Klawans HL, Shannon KM, Comella CL, Witt T (1990) Autologous transplantation of adrenal medulla in Parkinson's patients. Arch Neurol 47:1286-1289.

O'Malley EK, Black IB, Dreyfus CF (1991) Local support cells promote survival of substantia nigra dopaminergic neurons in culture. Exp Neurol 112:40-48.

Poltorak M, Freed WJ (1989) Immunological reactions induced by intracerebral transplantation: evidence that host microglia but not astroglia are the antigen-presenting cells. Exp Neurol 103:222-233.

Poltorak M, Shimoda K, Freed WJ (1992) L1 substrate enhances outgrowth of tyrosine-hydroxylase immunoreactive neurites in mesencephalic cell culture. Exp Neurol 117:176-184.

Prochiantz A, Daguent MC, Herbert A, Glowinski J (1981) Specific stimulation of in vitro maturation of mesencephalic dopaminergic neurons by striatal membranes. Nature 293:570-572.

Rathjen FG, Schachner M (1984) Immunocytological and biochemical characterization of a new neuronal cell surface component (L1 antigen) which is involved in cell adhesion. EMBO J 3:1-10.

Rogers SL, Letourneau PC, Pech IV (1989) The role of fibronectin in neural development. Dev Neurosci 11:248-265.

Schachner M (1983) Immunohistochemistry and immunocytochemistry of neural cell types in vitro and in situ. In: Immunohistochemistry. IBRO Handb Ser Methods Neurosci 3:399-429.
Schachner M (1991) Cell surface recognition and neuron-glia interactions. Ann NY Acad Sci 633:105-112.

Schachner M, Faissner A, Kruse J, Linder J, Meier DH, Rathjen FG, Wernecke H (1983) Cell type-specificity and developmental expression of cell surface components involved in cell interactions and of structurally related molecules. Cold Spring Harbor Symp Quant Biol 48:557-568.

Schachner M, Antonicek H, Fahring T, Faissner A, Fisher G, Kunemund V, Martini R, Meier E, Persohn E, Pollenberg E, Probsmeier R, Sadoul K (1990) Families of neural cell adhesion molecules. In: Morphoregulatory molecules (Edelman GM, Cunningham BA, Thiery J-P, eds), pp 443-468. New York: Wiley.

Schneider JS, Yuwiler A, Markham CH (1987) Selective loss of subpopulations of ventral mesencephalic dopaminergic neurons in the monkey following exposure to MPTP. Brain Res 411:144-150.

Schwab ME, Caroni P (1988) Oligodendrocytes and CNS myelin are non-permissive substrates for neurite growth and fibroblast spreading in vitro. J Neurosci 8:2381-2394.

Shults CW, Kimber TA (1992) Mesencephalic dopaminergic cells exhibit increased density of neural cell adhesion molecule and polysialic acid during development. Dev Brain Res 65:161-172.

Snow DM, Steindler DA, Silver J (1990a) Molecular and cellular characterization of the glial roof plate of the spinal cord and optic tectum: a possible role for a proteoglycan in the development of an axon barrier. Dev Biol 138:359-376.

Snow DM, Lemmon V, Carrino DA, Caplan AI, DA, Silver J (1990b) Sulfate proteoglycans present in astroglial barriers during development in vivo inhibit neurite outgrowth in vitro. Exp Neurol 109:111130.

Spring J, Beck K, Chiquet-Ehrismann R (1989) Two contrary functions of tenascin: dissection of the active sites by recombinant tenascin fragments. Cell 59:325-334.

Stallcup WB, Beasley LL, Levine JM (1985) Antibody against nerve growth factor-inducible large external (NILE) glycoprotein labels nerve fiber tracts in the developing rat nervous system. J Neurosci 5:10901101 .

Steindler DA, Cooper NG, Faissner A, Schachner M (1989) Boundaries defined by adhesion molecules during development of the cerebral cortex: the $\mathrm{J} 1 /$ tenascin glycoprotein in the mouse somatosensory cortical barrel field. Dev Biol 131:243-260.

Steindler DA, O'Brien TF, Laywell E, Harrington K, Faissner A, Schachner M (1990) Boundaries during normal and abnormal brain development of the cerebral cortex: in vitro and in vivo studies of glia and glycoconjugates. Exp Neurol 109:35-56.

Stewart GR, Pearlman AL (1987) Fibronectin-like immunoreactivity in the developing cerebral cortex. J Neurosci 7:3325-3333.

Streit WJ, Kreutzberg GW (1988) Response of endogenous glial cells to motor neuron degeneration induced by toxin ricin. J Comp Neurol 268:248-263.

Sudnof TC, Jahn R (1991) Proteins of synaptic vesicles involved in exocytosis and membrane recycling. Neuron 6:665-677.

Tomaselli KJ, Reichardt IF, Bixby JI. (1986) Distinct molecular interactions mediate neuronal process outgrowth on extracellular matrices and nonneuronal cell surfaces. J Cell Biol 103:2659-2672.

Tomaselli KJ, Neugebauer, KM, Bixby JL, Lilien J, Reichardt LF (1988) $\mathrm{N}$-Cadherin and integrins: two receptor systems that mediate neuronal process outgrowth on astrocyte surfaces. Neuron 1:33-43.

Tomazawa Y, Appel SH (1986) Soluble striatal extracts enhance development of mesencephalic dopaminergic neurons in vitro. Brain Res 399:111-124.

Walicke PA (1988) Interactions between basic fibroblast growth factor (FGF) and glycosoaminoglycans in promoting neurite outgrowth. Exp Neurol 102:144-148.

Zafra F, Hengerer B, Leibrock J, Toenen H, Lindholm D (1990) Activity dependent regulation of BDNF and NGF mRNAs in the rat hippocampus is mediated by non-NMDA glutamate receptors. EMBO J 9:3545-3550. 